\title{
Left Ventricular Hypertrophy in Patients with X-Linked Hypophosphataemia
}

\author{
(D) Ana Castellano-Martinez ${ }^{1}$, (I) Silvia Acuñas-Soto ${ }^{1}$, (D) Virginia Roldan-Cano, (D) Moises Rodriguez-Gonzalez² \\ 1 Puerta del Mar University Hospital, Department of Pediatric Nephrology, Cadiz, Spain \\ 2 Puerta del Mar University Hospital, Department of Pediatric Cardiology, Cadiz, Spain
}

\begin{abstract}
What is already known on this topic?
$\mathrm{X}$-linked hypophosphataemia is a rare disorder with well-known mechanisms leading to low phosphorus levels, but it does not clearly explain the cardiovascular involvement of these patients. Burosumab is a novel therapy for this entity, but it is not yet known whether early treatment can prevent complications, including cardiac manifestations.
\end{abstract}

\section{What this study adds?}

We report two patients with X-linked hypophosphataemia under burosumab therapy, one of them with a more severe phenotype associated with cardiac damage in the form of left ventricular hypertrophy. This patient had pre-existing cardiac involvement while receiving conventional treatment, which was not reversed after the start of burosumab therapy, although there was no worsening after start of burosumab.

\begin{abstract}
X-linked hypophosphatemia (XLH) is a rare genetic disorder with X-linked dominant inheritance. Mutations in the PHEX gene increase fibroblast growth factor 23 (FGF23) concentrations, causing loss of phosphorus at the proximal tubule. Most pediatric patients debut in the first two years with short stature and bowed legs. Conventional treatment consists of oral supplements with phosphorus and calcitriol. Since 2018, burosumab has been approved as a novel therapeutic option for XLH, with promising results. The purpose of this study was to share our experience with two cases of XLH treated with burosumab. These patients presented with a broad phenotypical differences. One had the most severe radiological phenotype and developed left ventricular hypertrophy (LVH) and left ventricular dysfunction with preserved ejection fraction. Treatment with burosumab was well-tolerated and was followed by radiological stability and a striking improvement in both blood biochemistry and quality of life. The LVH was stable and left ventricular function normalized in the patient with cardiac involvement. In recent years many studies have been carried out to explain the role of FGF23 in cardiovascular damage, but the exact pathophysiological mechanisms are as yet unclear. The most intensively studied populations are patients with XLH or chronic kidney disease, as both are associated with high levels of FGF23. To date, cardiovascular involvement in XLH has been described in patients treated with conventional treatment, so it would be of interest to investigate if early use of burosumab at the time of diagnosis of XLH would prevent the occurrence of cardiovascular manifestations.
\end{abstract}

Keywords: X-linked hypophosphataemia, FGF23, arterial hypertension, cardiovascular risk, left ventricular hypertrophy, burosumab

\section{Introduction}

X-linked hypophosphataemia (XLH) is a dominant genetic disorder caused by mutations in the PHEX gene (Xp22.1) and constitutes one of the leading causes of inherited hypophosphataemia with a prevalence of 4.8 per 100,000 (1). The key physiopathological mechanism seems to be an increased production of fibroblast growth factor 23 (FGF23) by osteocytes and osteoblasts due to a loss of function in the PHEX gene (2). FGF23 acts on the proximal renal tubule binding to the Klotho-FGF receptor complex, inhibiting phosphate reabsorption and calcitriol production, leading to chronic hypophosphataemia (3).
Address for Correspondence: Ana Castellano-Martinez MD, Puerta del Mar University Hospital, Department of Pediatric Nephrology, Cadiz, Spain Phone: + 34956002700 E-mail: anacastellanomart@gmail.com ORCID: orcid.org/0000-0001-7563-1235

${ }^{\circ}$ Copyright 2022 by Turkish Society for Pediatric Endocrinology and Diabetes

The Journal of Clinical Research in Pediatric Endocrinology published by Galenos Publishing House.
Conflict of interest: None declared Received: 01.12.2020 Accepted: 21.02 .2021 
Most pediatric patients with XLH manifest their first clinical symptoms in the first two years of life, presenting with disproportionate shortness and bone deformities, especially of the lower limbs, and craniosynostosis. Other complications, such as enthesopathy, osteomalacia, dental abscesses or hearing loss, often appear throughout the lives of these patients (4). There is a broad phenotypic spectrum even among family members. Consequently, a genotype-phenotype correlation is not well described (5). The conventional treatment consists of oral administration of phosphorus and calcitriol but these supplementary therapies do not inhibit the action of the high levels of FGF23, and they do not stop the progression of the disease.

In 2018, burosumab, a human monoclonal IgG1 antibody that neutralizes FGF23 was approved for the treatment of XLH (6). Since then, burosumab has shown promising results with clinical improvement and quality of life for these patients (7). Our aim was to share our experience with this novel treatment in two pediatric patients with different phenotypic patterns of XLH, focusing on cardiovascular complications in this population.

\section{Case Report}

The first case is a male patient diagnosed with XLH at 22 months of age during the investigation of his shortness and bowing of limbs (Figure 1). Hypophosphataemia with hyperphosphaturia (Table 1) was detected, and mutations in the PHEX gene were examined by next-generation sequencing (NGS) (8) with detection of a hemizygotic mutation. Therefore, he was started on conventional oral treatment. Poor biochemical and radiographic control persisted, despite good therapeutic compliance, requiring hemi-epiphysiodesis at 4 years old due to the significant deformity in the lower limbs. This led to walking disturbance and there was no improvement whatsoever. At the age of six, a first cardiovascular assessment with ambulatory blood pressure monitoring (ABPM), electrocardiogram (ECG), and echocardiography was carried out. The ABPM and ECG demonstrated no alterations, but the echocardiography revealed a concentric, non-obstructive, left ventricular hypertrophy (LVH) and associated subclinical left ventricular dysfunction parameters. Multiple criteria for definition of LVH in this patient were assessed (Table 1). The left ventricular ejection fraction was in the normal range $(>50 \%)$, but this parameter only assesses the systolic function and it is usually altered only in patients

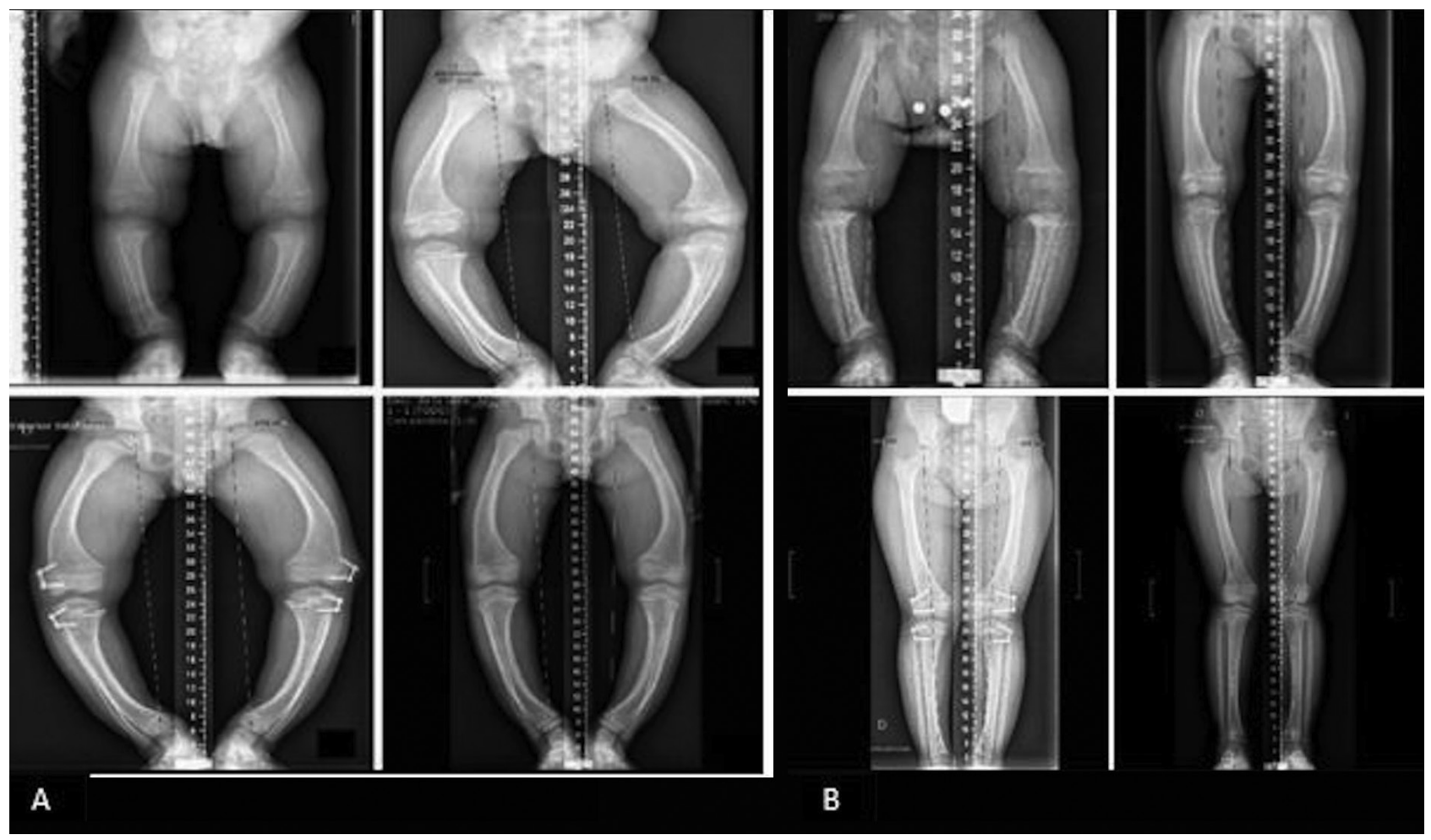

Figure 1. Radiological evolution of the patients. A) Evolution of patient 1, requiring hemiepiphysiodesis at 4 years-old for 19 months which was not effective, withdrawn after starting treatment with burosumab. Upper left panel (1.75 years); Upper right panel (4 years); Bottom left panel (6 years); Bottom right panel (8 years). B) Evolution of patient 2, with less lower limb deformity with a correction after hemiepiphysiodesis at 5.5 years-old during 9 months. Upper left panel (2 years); Upper right panel (5 years); Bottom left panel (6 years); Bottom right panel (9 years) 


\begin{tabular}{|c|c|c|c|c|c|c|}
\hline \multirow[t]{2}{*}{ Variable } & \multicolumn{3}{|l|}{ Patient 1} & \multicolumn{3}{|l|}{ Patient 2} \\
\hline & Debut & $\begin{array}{l}\text { Before } \\
\text { burosumab }\end{array}$ & Last follow-up & Debut & $\begin{array}{l}\text { Before } \\
\text { burosumab }\end{array}$ & Last follow-up \\
\hline \multicolumn{7}{|l|}{ Age and anthropomorphic measures } \\
\hline Age (yr) & 1.75 & 6 & 9 & 2 & 9 & 10 \\
\hline Weight (kg), (SD) & $14.2(+1.27)$ & $27.3(+0.71)$ & $35(+0.1)$ & $12(-0.85)$ & $28.8(-0.42)$ & $33(-0.36)$ \\
\hline Height (cm), (SD) & $83.5(-2.32)$ & $111.7(-1.83)$ & $129(-1.27)$ & $79.7(-2.99)$ & $116.5(-2.9)$ & $124(-2.42)$ \\
\hline BSA (m², by Mosteller) & 0.57 & 0.92 & 1.12 & 0.51 & 0.96 & 1.06 \\
\hline LBM (Kg, by Peters) & - & 21 & 27.4 & - & 22.5 & 25.7 \\
\hline BMI $\left(\mathrm{kg} / \mathrm{m}^{2}\right)$ & 20.4 & 21.9 & 21 & 18.9 & 21.2 & 21.5 \\
\hline PHEX mutation & \multicolumn{3}{|c|}{ Hemizygosis c.670c > T(p. [Gln224*]) } & \multicolumn{3}{|c|}{ Heterozygosis c.1061 c > T(p.Pro534Leu) } \\
\hline \multicolumn{7}{|l|}{ Laboratory (reference values) } \\
\hline Calcium (mg/dL) & $9.2(9.4-10.8)$ & $9.6(9.4-10.3)$ & $9.2(9.4-10.3)$ & $9.9(9.4-10.8)$ & $10.2(9.4-10.3)$ & $9.8(9.3-10.3)$ \\
\hline Phosphate (mg/dL) & $2.2(4.5-6.5)$ & $2.5(3.6-5.8)$ & $3.4(3.6-2.8)$ & $2.4(4.5-6.5)$ & $1.8(3.6-5.8)$ & $3.5(3.6-5.8)$ \\
\hline ALP (40-462 mg/dL) & 539 & 576 & 313 & 486 & 397 & 307 \\
\hline PTH (15-85 pg/mL) & 77 & 30.6 & 63.2 & 46.7 & 156.6 & 68 \\
\hline 25-OH-vitamin D (21-100 ng/mL) & 24.9 & 29.4 & 40.7 & 21.3 & 24.9 & 39 \\
\hline 1.25-OH-D-vitamin (16-56 pg/mL) & 106 & 44 & 42 & 30 & 36 & 41 \\
\hline FGF23 c-terminal ( $<145$ RU/mL) & $>427$ & $>427$ & $>427$ & $>427$ & $>427$ & $>427$ \\
\hline $\operatorname{TRP}(>85 \%)$ & 70 & 54.4 & 86 & 80 & 30 & 98 \\
\hline Tmp/GFR (mg/100 mL) & $1.556(5.1 \pm 0.9)$ & $1.674(4.6 \pm 0.6)$ & $3.311(4.6 \pm 0.6)$ & $2.032(5.1 \pm 0.9)$ & $0.976(4.6 \pm 0.6)$ & $2.973(4.6 \pm 0.6)$ \\
\hline $\mathrm{Ca} / \mathrm{Cr}(0.2 \mathrm{mg} / \mathrm{mg})$ & 0.15 & 0.08 & 0.18 & 0.06 & 0.04 & 0.09 \\
\hline Nephrocalcinosis & No & & & No & & \\
\hline \multicolumn{7}{|c|}{ Ambulatory blood pressure monitoring } \\
\hline $24 \mathrm{~h}$ mean SBP percentile & - & p86 & p89 & - & p90 & p89 \\
\hline 24h mean DBP percentile & - & p70 & p77 & - & p89 & p84 \\
\hline SBP load (\%) & - & 12 & 15 & - & 13 & 10 \\
\hline DBP load (\%) & - & 14 & 11 & - & 9 & 11 \\
\hline Nocturnal dipping & - & Yes & Yes & - & Yes & Yes \\
\hline \multicolumn{7}{|l|}{ Echocardiography } \\
\hline $\begin{array}{l}\text { Diameter of IVS for BSA, mm } \\
\text { (Z-score) }\end{array}$ & - & $12(3.44)$ & $11.5(2.89)$ & - & $8(1.46)$ & $8.5(1.57)$ \\
\hline LVM (g) & - & 115 & 126 & - & 60.3 & 72.5 \\
\hline LVMI > $51\left(\mathrm{~g} / \mathrm{m}^{2} .7\right)$ & & Yes & Yes & - & Yes & Yes \\
\hline $\begin{array}{l}\text { LVM }(\mathrm{g}) / \mathrm{BSA} \text { ( } \mathrm{LVH}>115 \text { in boys } \\
\text { and }>95 \text { in girls) }\end{array}$ & & 125 & 112.5 & & 62.8 & 71 \\
\hline LVM for BSA (Z-score) & - & 3.65 & 2.75 & - & -0.12 & 0.38 \\
\hline $\mathrm{LVM} / \mathrm{m}^{2.7}$ (percentile for age) & - & $85.3\left(>99^{\text {th }}\right)$ & $63.3\left(>99^{\text {th }}\right)$ & - & $39.9\left(95-99^{\text {th }}\right)$ & $40.5\left(95-99^{\text {th }}\right)$ \\
\hline $\begin{array}{l}\mathrm{LVM} /\left[\left(\mathrm{m}^{2.16}\right)+0.09\right] \\
\left(>45 \mathrm{~g} / \mathrm{m}^{2.16}=\mathrm{LVH}\right)\end{array}$ & - & 84.5 & 69.1 & - & 43.3 & 43.1 \\
\hline LVM percentile for LBM & - & $>97^{\text {th }}$ & $93^{\text {rd }}$ & - & $5^{\text {th }}$ & $10^{\text {th }}$ \\
\hline LV Tei index ( $>0.50=$ dysfunction) & - & 0.57 & 0.42 & - & 0.35 & 0.41 \\
\hline $\operatorname{LVEF}(\%)(<50 \%=$ dysfunction $)$ & - & 63 & 67 & - & 65 & 67 \\
\hline \multicolumn{7}{|c|}{$\begin{array}{l}\text { For definition of LVH a total of five different criteria were assessed. } \\
\text { Yr: years, SD: standard deviation, BSA: body surface area, LBM: lean body mass, BMI: body mass index, ALP: alkaline phosphatase, PTH: parathyroid hormone, FGF23: } \\
\text { fibroblast growth factor 23, TRP: tubular reabsorption of phosphate, Tmp/GFR: maximal tubular phosphate reabsorption per } 100 \mathrm{~mL} \text { of filtrate, Ca/Cr: urine calcium/ } \\
\text { creatinine ratio, ABPM: ambulatory blood pressure monitoring, SBP: systolic blood pressure, DBP: diastolic blood pressure, IVS: interventricular septum, LVMI: left } \\
\text { ventricular mass index, LVM: left ventricle mass, LV: left ventricle, LVEF: left ventricular ejection fraction }\end{array}$} \\
\hline
\end{tabular}


with clinically evident heart failure. To evaluate subclinical ventricular dysfunction, the Tei index was used, a parameter that includes both systolic and diastolic time intervals to assess global cardiac dysfunction and detect early cardiac dysfunction in asymptomatic patients (9). The Tei index is an easily performable, recordable and reproducible parameter that is influenced by age, sex, heart rate, and cardiac load conditions. A Tei index $<0.5$ is the upper limit of normal ( 2 Z-scores), and our patient presented with a Tei index value of 0.57 .

At this point in 2017, it was decided to start burosumab (0.7 $\mathrm{mg} / \mathrm{kg}$ every 15 days) as compassionate treatment. After 3 years of treatment at a dose of $1.2 \mathrm{mg} / \mathrm{kg}$ every 15 days, the treatment has been well tolerated without significant side-effects. His serum phosphorus concentrations have increased to near normal values for his age. We have also noticed a slow progression of the lower limbs' deformities with a significant improvement in quality of life (Figure 1A). Regarding the cardiovascular involvement, the dimensions of the left ventricle have remained stable, with a persistent LVH but with relatively reduced left ventricular mass index (LVMI) (Table 1). The left ventricular function has normalized (Tei index <0.5).

The second case was a female patient diagnosed with $\mathrm{XLH}$ at 24 months old during a study of genu varus. She had hypophosphataemia with hyperphosphaturia (Table 1), and we found a heterozygous mutation in the PHEX gene by NGS. She received conventional treatment, with persisting hypophosphataemia and worsening of the lower limb deformities (Figure 1B). Thus, she required hemiepiphysiodesis at 5.5 years-old, which was effective. The patient continued with hypophosphataemia and also very poor gastrointestinal tolerance to oral phosphorus. Therefore, we decided to start burosumab treatment $(0.4 \mathrm{mg} / \mathrm{kg}$ every 15 days) at 9 years old (2019). ABPM, ECG and echocardiography were uneventful without signs of arterial hypertension, LVH, or left ventricular dysfunction. After 1.5 years, the treatment has been well tolerated. The hypophosphataemia has improved, she maintains good radiological progress and her intestinal symptoms have disappeared. The cardiovascular assessment remains normal. Informed consent was obtained from both patients' parents.

\section{Discussion}

Herein, we present two patients with XLH with different phenotypic expression. According to his records, the patient with the most severe radiological phenotype was diagnosed with LVH and left ventricular dysfunction by tissue Doppler echocardiography.
The definition of LVH is still controversial in children with multiple and variable existing criteria. The most commonly employed methods are adjusted for body surface area (BSA) or height, usually to an allometric power as the relationship between left ventricular mass (LVM) to height is not linear. Daniels et al. (10) suggested the use of height ${ }^{2.7}$ for indexing LVM based on studies relating LVM to lean body mass (LBM) in older children. This boy fulfilled the LVH definitions recommended by current pediatric arterial hypertension guidelines (11): LVMI $>51 \mathrm{~g} / \mathrm{m}^{2.7}$, LVM $>115 \mathrm{~g} / \mathrm{BSA}$ and LVM $>95^{\text {th }}$ percentile for age (12). Some authors raise the question of whether a higher cut-off ( $99^{\text {th }}$ vs $95^{\text {th }}$ percentile) should be used, and our patient also met this condition (13).

The utility of LVM/height ${ }^{2.7}$ in children has been questioned due to the index variation in the lower age and lower height groups $(14,15)$. Thus, XLH patients usually present a low height for their age, and these criteria could lead to an overestimation of LVMI and LVH diagnosis in this population. Chinali et al. (14) showed that the allometric power of 2.16 provides the best-fit model. This method provides normal reference values of LVMI, even for children under $140 \mathrm{~cm}$ of height, which is more appropriate for XLH patients. In particular, a LVMI greater than $45 \mathrm{~g} / \mathrm{m}^{2.16}$ would represent the $95^{\text {th }}$ percentile across the whole pediatric age range, independent of the sex and height, to identify LVH, and our patient also met this criterion. Other LVH criteria assessed in this case were a LVM > 2.5 Z-scores for BSA (16) and an interventricular septum diastolic diameter $>2.5 \mathrm{Z}$-scores for BSA (17).

The normalization of the LVM to various functions of height, $\mathrm{BSA}$, or body mass index (BMI) can alter the interpretation and classification of LVH in children. LVM varies in proportion to LBM but is usually expressed relative to height or BSA, each of which functions as a surrogate for LBM. Foster et al. (15) provided normal percentiles of LVM for LBM, and our patient presented as $>97^{\text {th }}$ percentile of LVM for LBM in the first echocardiographic control. Despite the existing controversy and the absence of definitive LVH criteria, particularly in low height populations, we provided data that patient 1 met multiple criteria for LVH. Patient 2 only fulfilled the LVH criteria of LVMI $>51 \mathrm{~g} / \mathrm{m}^{2.7}$ and LVMI $\left(\mathrm{g} / \mathrm{m}^{2.7}\right)>95^{\text {th }}$ percentile for age, reinforcing the need to use specific criteria for the correct assessment of LVH in this population.

$\mathrm{XLH}$ is actually associated with LVH and its relationship with FGF23 levels and arterial hypertension as causative mechanisms in this setting remain uncertain, as reflected by the controversial published literature. Takashi et al. (18) did not observe LVH in 10 adults with XLH. Pastor-Arroyo et al. (19) studied the increased risk of cardiovascular 
disease in XLH mouse models (PhexC733R), which showed increased FGF23 and parathyroid hormone (PTH) levels, hypophosphataemia, low $1.25(\mathrm{OH}) 2$ vitamin D levels, and low soluble Klotho, but not arterial hypertension, LVH or cardiac dysfunction. Similar results were found in the study of Liu et al. (20) in male Hyp mouse model of XLH. HernándezFrías et al. (21) reported twenty-four pediatric patients with $\mathrm{XLH}$ and they observed LVH in $18 \%$. They did not find correlation with FGF23 levels and only one case presented with associated arterial hypertension. Accordingly, although our patient with LVH showed the most severe radiological phenotype of XLH, both cases presented with high levels of FGF23 and normal ranges of blood pressure. Therefore, pathophysiological mechanisms different than increased FGF23 and arterial hypertension might be involved in the development of LVH in XLH patients.

However, recent evidence has suggested a role for FGF23 in the development of cardiovascular involvement in XLH, particularly LVH and hypertension. Studies in animal models showed that FGF23 increased intracellular calcium levels, stimulating cardiac muscle contractility, with subsequent LVH. Abnormal calcium deposition in the vascular tissue causing arterial hypertension and subsequent LVH in relation with increased FGF23 has also been reported $(22,23)$. Nehgme et al. (24) studied thirteen patients with XLH with an average age of 13.5 years. They found $\mathrm{LVH}$ in $54 \%$ of cases, but they did not investigate the correlation with FGF23 levels. However, they proved that all patients with XLH had significantly higher diastolic blood pressure (DBP) than the control group at the peak of exercise ergometry. While the association of arterial hypertension with LVH was not assessed, these results suggest that XLH patients manifest specific vascular dysregulation in association with the development of LVH. It should be noted that in pediatric patients (1-18 years), hypertension is defined as average clinic-measured systolic blood pressure (SBP) or DBP $\geq 95^{\text {th }}$ percentile (based on age, sex, and height percentiles). In recent years the American Academy of Paediatrics has updated the guidelines with new reference values for the pediatric population, which should be used to avoid misclassification of hypertensive patients $(11,25)$. The relationship between elevated levels of FGF23 and cardiovascular impairment, including LVH, has been widely investigated outside the XLH setting. It is known that chronic kidney disease (CKD) is associated with high levels of FGF23 and a deficiency of the co-receptor Klotho. The cardiovascular affectation seems to be directly caused by FGF23 by activating the intermediate molecule FGFR4, as myocytes do not express Klotho (26). Mitsnefes et al. (27) investigated the association of increased FGF23 and LVH in 587 pediatric patients with mild-moderate
CKD. Interestingly, they showed a significant relationship between these two variables independent of SBP values.

\section{Conclusion}

Further studies would be necessary to clarify the exact mechanisms involved in developing cardiovascular manifestations in XLH. The LVH observed in one of our patients highlights the utility of serial cardiovascular assessment, including serial blood pressure determination, ECG and echocardiography, as well as the promotion of adequate control of cardiovascular risk factors in this population. In our short-term experience, burosumab is an excellent therapeutic option for XLH in children, as it improves their quality of life and allows rapid biochemical stabilization without significant side effects. As was documented, there is a hypothetical role for the use of burosumab in stabilizing the LVH and normalizing the left ventricular function in XLH patients. Burosumab did not have an effect on reversing already established LVH in the patient with this, but it could similarly slow the progression as it does with radiological manifestations. It would be of interest to investigate if early use of burosumab at the time of diagnosis of XLH would prevent the occurrence of cardiovascular manifestations.

\section{Ethics}

Informed Consent: Consent form was filled out by all participants.

Peer-review: Externally peer-reviewed.

\section{Authorship Contributions}

Surgical and Medical Practices: Ana Castellano-Martinez, Silvia Acuñas-Soto, Virginia Roldan-Cano, Moises Rodriguez-Gonzalez, Concept: Ana Castellano-Martinez, Moises Rodriguez-Gonzalez, Design: Ana CastellanoMartinez, Moises Rodriguez-Gonzalez, Data Collection or Processing: Silvia Acuñas-Soto, Virginia Roldan-Cano, Analysis or Interpretation: Silvia Acuñas-Soto, Virginia Roldan-Cano, Literature Search: Ana Castellano-Martinez, Silvia Acuñas-Soto, Virginia Roldan-Cano, Moises RodriguezGonzalez, Writing: Ana Castellano-Martinez, Silvia AcuñasSoto, Virginia Roldan-Cano, Moises Rodriguez-Gonzalez.

Financial Disclosure: The authors declared that this study received no financial support.

\section{References}

1. Haffner D, Emma F, Eastwood DM, Duplan MB, Bacchetta J, Schnabel D, Wicart P, Bockenhauer D, Santos F, Levtchenko E, Harvengt P, Kirchhoff M, Di Rocco F, Chaussain C, Brandi ML, Savendahl L, Briot K, Kamenicky P, Rejnmark L, Linglart A. Clinical practice 
recommendations for the diagnosis and management of X-linked hypophosphataemia. Nat Rev Nephrol 2019;15:435-455.

2. Fukumoto S. FGF23-related hypophosphatemic rickets/osteomalacia: diagnosis and new treatment. J Mol Endocrinol 2021;66:R57-R65.

3. Giralt M, Chocron S, Ferrer R, Ariceta G. Plasma intact fibroblast growth factor 23 level is a useful tool for diagnostic approach of renal hypophosphatemia. Pediatr Nephrol 2021;36:1025-1028. Epub 2021 Jan 25.

4. Dahir K, Roberts MS, Krolczyk S, Simmons JH. X-Linked Hypophosphatemia: A New Era in Management. J Endocr Soc 2020;4:bvaa 151.

5. Scialla JJ, Wolf M. Roles of phosphate and fibroblast growth factor 23 in cardiovascular disease. Nat Rev Nephrol 2014;10:268-278. Epub 2014 Apr 1

6. Padidela R, Cheung MS, Saraff V, Dharmaraj P. Clinical guidelines for burosumab in the treatment of XLH in children and adolescents: British paediatric and adolescent bone group recommendations. Endocr Connect 2020;9:1051-1056.

7. Martín Ramos S, Gil-Calvo M, Roldán V, Castellano Martínez A, Santos F. Positive Response to One-Year Treatment With Burosumab in Pediatric Patients With X-Linked Hypophosphatemia. Front Pediatr 2020;8:48.

8. Thiele S, Werner R, Stubbe A, Hiort O, Hoeppner W. Validation of a next-generation sequencing (NGS) panel to improve the diagnosis of X-linked hypophosphataemia (XLH) and other genetic disorders of renal phosphate wasting. Eur J Endocrinol 2020;183:497-504.

9. Cui W, Roberson DA. Left ventricular Tei index in children: comparison of tissue Doppler imaging, pulsed wave Doppler, and M-mode echocardiography normal values. J Am Soc Echocardiogr 2006; 19:1438-1445.

10. Daniels SR, Kimball TR, Morrison JA, Khoury P, Witt S, Meyer RA. Effect of lean body mass, fat mass, blood pressure, and sexual maturation on left ventricular mass in children and adolescents. Statistical, biological, and clinical significance. Circulation 1995;92:3249-3254.

11. Flynn JT, Kaelber DC, Baker-Smith CM, Blowey D, Carroll AE, Daniels SR, de Ferranti SD, Dionne JM, Falkner B, Flinn SK, Gidding SS, Goodwin C, Leu MG, Powers ME, Rea C, Samuels J, Simasek M, Thaker VV, Urbina EM; SUBCOMMITTEE ON SCREENING AND MANAGEMENT OF HIGH BLOOD PRESSURE IN CHILDREN. Clinical Practice Guideline for Screening and Management of High Blood Pressure in Children and Adolescents. Pediatrics 2017;140:e20171904. Epub 2017 Aug 21

12. Khoury PR, Mitsnefes M, Daniels SR, Kimball TR. Age-specific reference intervals for indexed left ventricular mass in children. J Am Soc Echocardiogr 2009;22:709-714. Epub 2009 May 7

13. Gidding SS. Assessment of Left Ventricular Mass in Children and Adolescents: Current Status. J Pediatr 2016;170:12-14. Epub 2015 Dec 31

14. Chinali M, Emma F, Esposito C, Rinelli G, Franceschini A, Doyon A, Raimondi F, Pongiglione G, Schaefer F, Matteucci MC. Left Ventricular Mass Indexing in Infants, Children, and Adolescents: A Simplified Approach for the Identification of Left Ventricular Hypertrophy in Clinical Practice. J Pediatr 2016;170:193-198. Epub 2015 Dec 6

15. Foster BJ, Khoury PR, Kimball TR, Mackie AS, Mitsnefes M. New Reference Centiles for Left Ventricular Mass Relative to Lean Body
Mass in Children. J Am Soc Echocardiogr 2016;29:441-447. Epub 2016 Feb 3

16. Foster BJ, Mackie AS, Mitsnefes M, Ali H, Mamber S, Colan SD. A novel method of expressing left ventricular mass relative to body size in children. Circulation 2008;117:2769-2775. Epub 2008 May 19

17. Pettersen MD, Du W, Skeens ME, Humes RA. Regression equations for calculation of $z$ scores of cardiac structures in a large cohort of healthy infants, children, and adolescents: an echocardiographic study. J Am Soc Echocardiogr 2008;21:922-934. Epub 2008 Apr 11

18. Takashi Y, Kinoshita Y, Hori M, Ito N, Taguchi M, Fukumoto S. Patients with FGF23-related hypophosphatemic rickets/osteomalacia do not present with left ventricular hypertrophy. Endocr Res 2017;42:132137. Epub 2016 Oct 18

19. Pastor-Arroyo EM, Gehring N, Krudewig C, Costantino S, Bettoni C, Knöpfel T, Sabrautzki S, Lorenz-Depiereux B, Pastor J, Strom TM, Hrabě de Angelis M, Camici GG, Paneni F, Wagner CA, Rubio-Aliaga I. The elevation of circulating fibroblast growth factor 23 without kidney disease does not increase cardiovascular disease risk. Kidney Int 2018;94:49-59. Epub 2018 May 5

20. Liu ES, Thoonen R, Petit E, Yu B, Buys ES, Scherrer-Crosbie M, Demay MB. Increased Circulating FGF23 Does Not Lead to Cardiac Hypertrophy in the Male Hyp Mouse Model of XLH. Endocrinology 2018;159:21652172 .

21. Hernández-Frías O, Gil-Peña H, Pérez-Roldán JM, González-Sanchez S, Ariceta G, Chocrón S, Loza R, de la Cerda Ojeda F, Madariaga L, Vergara I, Fernández-Fernández M, Ferrando-Monleón S, Antón-Gamero M, Fernández-Maseda Á, Luis-Yanes MI, Santos F. Risk of cardiovascular involvement in pediatric patients with X-linked hypophosphatemia. Pediatr Nephrol 2019;34:1077-1086. Epub 2019 Jan 4

22. Faul C, Amaral AP, Oskouei B, Hu MC, Sloan A, Isakova T, Gutiérrez OM, Aguillon-Prada R, Lincoln J, Hare JM, Mundel P, Morales A, Scialla J, Fischer M, Soliman EZ, Chen J, Go AS, Rosas SE, Nessel L, Townsend RR, Feldman HI, St John Sutton M, Ojo A, Gadegbeku C, Di Marco GS, Reuter S, Kentrup D, Tiemann K, Brand M, Hill JA, Moe OW, Kuro-O M, Kusek JW, Keane MG, Wolf M. FGF23 induces left ventricular hypertrophy. J Clin Invest 2011;121:4393-4408. Epub 2011 Oct 10

23. Okamoto Y, Fujita S, Morita H, Kizawa S, Ito T, Sakane K, Sohmiya K, Hoshiga M, Ishizaka N. Association between circulating FGF23, $\alpha$-Klotho, and left ventricular diastolic dysfunction among patients with preserved ejection fraction. Heart Vessels 2016;31:66-73. Epub 2014 Sep 16

24. Nehgme R, Fahey JT, Smith C, Carpenter TO. Cardiovascular abnormalities in patients with X-linked hypophosphatemia. J Clin Endocrinol Metab 1997;82:2450-2454.

25. Macumber I. Ambulatory Blood Pressure Monitoring in Children and Adolescents: a Review of Recent Literature and New Guidelines. Curr Hypertens Rep 2017;19:96.

26. Haffner D, Leifheit-Nestler M. Extrarenal effects of FGF23. Pediatr Nephrol 2017;32:753-765. Epub 2016 Oct 4

27. Mitsnefes MM, Betoko A, Schneider MF, Salusky IB, Wolf MS, Jüppner H, Warady BA, Furth SL, Portale AA. FGF23 and Left Ventricular Hypertrophy in Children with CKD. Clin J Am Soc Nephrol 201 8;13:4552. Epub 2017 Oct 12 